\title{
Uso de malhas pigmentadas e mulching em túneis para cultivo de rúcula: efeito no ambiente e nas plantas modelo
}

\author{
Use of pigmented mesh covers tunnels and mulchings for growing roquette: environmental effects \\ on model plants
}

\author{
Rafael Ricardo Cantu ${ }^{\mathrm{I} *}$ Rumy Goto $^{\mathrm{II}}$ Richard Willian Junglaus $^{\mathrm{III}}$ Rogério Gonzatto \\ Antonio Ribeiro da Cunha ${ }^{\mathrm{II}}$
}

\section{RESUMO}

O uso de malhas pigmentadas em cultivos de hortaliças folhosas permite a melhor adequação do ambiente às plantas, com destaque para a rúcula. Essa hortaliça vem conquistando maior espaço no mercado consumidor brasileiro desde o final da década de 90. Essa pesquisa teve por objetivo avaliar as condições ambientais proporcionadas pelo uso de telas pigmentadas na cobertura de túneis de cultivo, relacionando com as respostas agronômicas da rúcula, cultivada dentro desses túneis sobre diferentes coberturas de solo. As coberturas de túneis foram: a Chromatinet ${ }^{\oplus}$ azul, Chromatinet ${ }^{\circledast}$ vermelha, tela $^{\circ}$ aluminizada prata, Sombrite ${ }^{\circledR} 50 \%$ e filme plástico transparente de polietileno de baixa densidade de $100 \mu$. As coberturas de solo, também denominadas mulchings, dentro dos túneis foram: o filme plástico de polietileno de cor preta; de polietileno de dupla-face nas cores preta e branca, com a face branca voltada para cima; casca de arroz e a ausência de mulching. $O$ delineamento utilizado foi o de blocos ao acaso com 24 tratamentos e três repetições. Nas condições do experimento, o emprego de algumas coberturas de túnel e de solo modificou o ambiente e melhorou as respostas agronômicas das plantas de rúcula.

Palavras-chave: Eruca vesicaria sativa, telas, ambientes de cultivo.

\section{ABSTRACT}

The use of pigmented screens for growing vegetable crops provides an opportunity for adjusting environmental conditions, especially for roquette. This vegetable crop is consumed mainly as raw, and has a large proportion in Brazilian vegetable market since 1990s. The present research was aimed to evaluate the effect the altered environmental conditions (by using pigmented screens tunnels) on agronomic performance of roquette, grown inside tunnels having different color covers. Coverage screens colors were blue, red, silver, screen of shading $50 \%$ and transparent plastic. Beside this the effect of different mulching practices was also evaluated inside the tunnels. The experiment was laid out under randomized complete blocks design with 24 treatments and three replications. The results of the experiment under such conditions changed environmental and soil conditions and resulted in improved agronomic response by roquette plants.

Key words: Eruca vesicaria sativa, screen, mulch, growth.

\section{INTRODUÇÃO}

No Brasil, o uso de cobertura de túneis para cultivo de hortaliças teve início nos anos 1960. Entretanto, no início da década de 90 é que a técnica passou a ser amplamente utilizada (SANTOS et al., 2010). Atualmente, o Brasil possui aproximadamente 17 mil hectares cultivados sob abrigos de cultivo principalmente nos Estados de São Paulo, Rio Grande do Sul e Minas Gerais, com grande potencial de expansão (BLISKA, 2011). Nas últimas décadas, o cultivo de plantas sob coberturas e sobre mulchings, revolucionou a produção de hortaliças, possibilitando condicionar o ambiente às necessidades das plantas e estender o período de produção para épocas do ano e regiões antes inaptas para determinados cultivos (ROCHA \& PURQUEIRO 2009; FIGUEIREDO, 2011).

$\mathrm{O}$ uso de telas pigmentadas em cobertura de túneis é recente no Brasil. Estas telas podem modificar a temperatura, a radiação, a umidade relativa e o efeito estufa que alteram o microclima

\footnotetext{
'Universidade Federal de Santa Maria (UFSM), 97105-900, Santa Maria, RS, Brasil. E-mail: rrcantu@epagri.sc.gov.br. *Autor para correspondência.

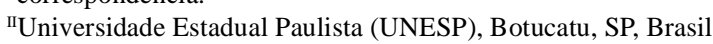

IIEmpresa de Pesquisa Agropecuária e Extensão Rural de Santa Catarina, (EPAGRI), Flor do Sertão, SC, Brasil.
} 
no interior de túneis (CUNHA \& GOTO, 2006; SANTOS et al., 2010). Entretanto, é importante avaliar as coberturas de túneis para cada local, épocas e espécie cultivada, referentes à temperatura umidade e sombreamento (RODRIGUES et al., 2008; STRECK et al., 2007).

Desde o final da década de 90, a rúcula (Eruca vesicaria sativa (Mill) Thell) vem ocupando maior espaço no mercado consumidor. Consumida como salada crua ou de outras formas, a rúcula se diferencia de outras saladas comumente conhecidas, principalmente pelo sabor característico (PURQUEIRO \& TIVELLI, 2006). Na maioria dos casos, o consumidor tem preferência por folhas tenras. Segundo dados da Companhia de Entrepostos e Armazéns Gerais do Estado de São Paulo (CEAGESP, 2011), o preço da rúcula atingiu a casa dos $R \$ 4,37 \mathrm{~kg}^{-1}$, superando o valor pago às principais folhosas comercializadas.

A pesquisa teve o objetivo de avaliar as condições ambientais em túneis de cultivo, cobertos com telas pigmentadas, relacionando com as respostas agronômicas da rúcula, cultivada dentro desses túneis sobre diferentes coberturas de solo, denominadas como mulchings.

\section{MATERIAL E MÉTODOS}

O experimento foi conduzido de março a maio de 2007, na Fazenda Experimental São Manuel, da FCA-UNESP, em São Manuel-SP, com coordenadas geográficas aproximadas de $22^{\circ} 44^{\prime} \mathrm{S}$ e $48^{\circ} 34^{\prime}$ WGr, com altitude média de $750 \mathrm{~m}$. Segundo a classificação de KOPPEN \& GEIGER (1927), o clima local é do tipo mesotérmico Cwa, subtropical úmido com estiagem no período de inverno. A precipitação média anual é de $1.534 \mathrm{~mm}$ com temperatura média anual de $21^{\circ} \mathrm{C}$, sendo $28^{\circ} \mathrm{C}$ a temperatura do mês mais quente e $17,5^{\circ} \mathrm{C}$ a do mês mais frio (ESPÍNDOLA et al., 1973). O solo é classificado como Latossolo Vermelho-amarelo fase arenosa (EMBRAPA, 2006).

As mudas de rúcula foram produzidas em bandejas de poliestireno expandido com 288 células, utilizando-se o substrato Plantmax $\mathrm{HT}^{\circledR}$. Cada célula recebeu seis sementes da cultivar 'Folha Larga ${ }^{\circledR}$ '. Após a emergência, as mudas foram desbastadas para se obter um conjunto de quatro plantas por célula.

As adubações de base e de cobertura foram realizadas com base na análise do solo e de acordo com o manual de adubação do Estado de São Paulo - Boletim 100 (TRANI et al., 1997). Foi aplicado na base $100 \mathrm{~g} \mathrm{~m}^{-2}$ de adubo mineral formulado 2-20-10. As adubações de cobertura foram feitas via fertirrigação, aos 15 e aos 30 dias após o plantio, com $22 \mathrm{~g} \mathrm{~m}^{-2} \mathrm{de}$ ureia por aplicação.

Aos 16 dias após a semeadura as mudas foram transplantadas para covas. Cada cova recebeu um conjunto de quatro plantas. A irrigação do experimento foi realizada por gotejamento. A colheita dos conjuntos de plantas foi realizada por meio de corte das folhas rente ao colo das plantas, aos 42 dias após o transplante das mudas.

O experimento constou de 24 tratamentos, sendo seis ambientes de plantio utilizando o delineamento blocos ao acaso no esquema fatorial de $6 \times 4$, cada um com quatro coberturas de solo (mulchings), a saber: mulching plástico de polietileno de cor preta (MP); mulching de polietileno de duplaface nas cores preta e branca, com a face branca voltada para cima (MD); casca de arroz (CA) e sem mulching (SM). Os mulchings foram distribuídos em blocos casualizados, dentro de cada ambiente, em três repetições. Os ambientes de plantio foram a céu aberto; em túneis cobertos com telas Chromatinet ${ }^{\circledR}$ (azul), com Chromatinet $^{\circledR}$ (vermelha), com tela aluminizada (prata), com tela de sombreamento $50 \%$ (sombrite) e com filme plástico transparente de polietileno de baixa densidade (PEBD) de $100 \mu$.

Cada ambiente tinha 2,5m de largura por $12 \mathrm{~m}$ de comprimento, dispostos lado a lado no sentido este-oeste e distantes de $1 \mathrm{~m}$ entre si. Os túneis foram montados com estruturas semicirculares de forma que a cobertura chegava próxima ao solo nas laterais e com $1,7 \mathrm{~m}$ de altura no centro. Em cada ambiente construíram-se dois canteiros, cada um com $1,0 \mathrm{~m}$ de largura e $12 \mathrm{~m}$ de comprimento, distantes $0,5 \mathrm{~m}$ entre si. Nos canteiros foram distribuídos os tratamentos de mulchings, em parcelas com 1,0m de largura por 2,0 de comprimento.

Cada parcela foi constituída de três linhas de plantio dispostas longitudinalmente e distanciadas de $0,2 \mathrm{~m}$ entre si. Cada linha recebeu oito conjuntos de plantas distanciados de 0,20m. Foram considerados úteis seis dos oito conjuntos de plantas internos da linha central.

A matéria fresca foi avaliada pela média do peso das plantas úteis, que foram acondicionadas em sacos plásticos na colheita e avaliadas imediatamente. A área foliar foi determinada pela área média das plantas úteis, medidas por meio do aparelho LI-COR modelo 3000. Nessa avaliação, foram utilizadas as mesmas plantas que serviram para avaliar a matéria fresca. A matéria seca foi determinada pela média do peso das plantas úteis, que foram secas em estufa a $60^{\circ} \mathrm{C}$, até atingir peso constante. $\mathrm{O}$ peso específico foliar foi estabelecido pela razão entre a matéria seca 
e a área foliar. As medições da temperatura e umidade relativa do ar foram feitas com um sensor automático modelo HMP45C (Vaisala) instalado a 1,5m de altura no centro do túnel, e conectado em datalogger modelo CR23X (Campbell Scientific, Inc.). A varredura do sensor foi feita a cada minuto e armazenando os valores médios a cada 30 minutos. A leitura da radiação fotossinteticamente ativa dentro dos ambientes de plantio foi estabelecida por meio do equipamento Írga. As medições foram semanais, sempre no período da manhã, aproximadamente às 10 horas.

Os resultados foram submetidos à análise da variância e as médias comparadas pelo teste de Tukey a 5\%, utilizando-se o programa estatístico Sisvar.

\section{RESULTADOS E DISCUSSÃO}

Houve diferença nas características microclimáticas produzidas dentro dos ambientes de cobertura de túneis (Tabela 1). O túnel com cobertura de PEBD proporcionou temperaturas mais elevadas que os tratamentos com cobertura de sombrite e tela prata. O tratamento de cobertura de tela vermelha proporcionou maior temperatura que o tratamento de cobertura de sombrite. Os tratamentos de cobertura com tela azul e céu aberto não diferiram dos demais. No túnel com cobertura de PEBD ocorreram as menores médias de umidade relativa do ar diferindo dos demais tratamentos. As maiores médias de umidade relativa do ar ocorreram nos túneis com cobertura de tela de sombreamento, prata, azul e a céu aberto diferido do tratamento com cobertura de tela vermelha, que apresentou médias menores que estes. (Tabela 1). A radiação fotossinteticamente ativa foi maior no campo, comparado aos demais tratamentos. A menor radiação foi encontrada no tratamento com cobertura de túnel prata.

Para a característica área foliar da rúcula ocorreu interação entre mulchings e os ambientes de plantio nos tratamentos de cobertura de túnel com tela vermelha e filme transparente de PEBD. No túnel coberto com tela vermelha, o tratamento com mulching MD proporcionou maior área foliar que o tratamento com mulching SM que não diferiram dos mulchings CA e MP. No túnel com cobertura de PEBD, o tratamento com mulching MP proporcionou maior área foliar que o tratamento com mulching SM, que não diferiram dos mulchings MD. Nessa característica, houve diferença entre os ambientes de plantio somente no tratamento da cobertura de solo com mulching MP. Esse tratamento apresentou maior área foliar no túnel com cobertura PEBD, entretanto, não diferindo dos túneis com cobertura de azul, vermelho e prata, e diferindo do túnel com cobertura de sombrite e a céu aberto tendo o ambiente de cobertura de PEBD com melhores resultados, entretanto, somente no tratamento de mulching MP (Tabela 2) e CA (Tabela 2).

$\mathrm{Na}$ produção de matéria fresca ocorreu interação entre mulchings e cobertura de túneis nos tratamentos de cobertura com tela vermelha e filme transparente de PEBD. No túnel com cobertura de tela vermelha, o tratamento com mulching MD proporcionou maior produção de matéria fresca da rúcula do que o tratamento mulching $\mathrm{SM}$, que não diferiram dos mulchings MP e CA. No túnel de cobertura de PEBD, os mulchings MD e MP proporcionaram maior produção de matéria fresca que o tratamento SM, que não diferiram do tratamento mulching CA. (Tabela 3).

O peso específico foliar da rúcula proporcionado pelo ambiente de cobertura de túnel PEBD, na média geral dos tratamentos de mulching, foi menor que o proporcionado pelo ambiente a céu aberto, que não diferiram dos demais ambientes (Figura 1).

De acordo com os resultados, o cultivo da rúcula nos ambientes sob túneis com coberturas

Tabela 1 - Temperatura média do ar, umidade relativa do ar e radiação fotossinteticamente ativa (RFA), obtidas em túneis de cultivo com diferentes coberturas através da estação de monitoramento ambiental Datalloger ${ }^{\circledR}$. FCA-UNESP, Botucatu (SP), 2006.

\begin{tabular}{lccc}
\hline Cobertura do túnel & Temperatura $\left({ }^{\circ} \mathrm{C}\right)$ & Umidade Relativa $(\%)$ & RFA $\left(\mathrm{MJ} \mathrm{m}^{-2}\right)$ \\
\hline Azul & $17,7 \mathrm{abc}^{1}$ & $76,4 \mathrm{a}$ & 3,10 \\
Vermelho & $18,1 \mathrm{ab}$ & $70,6 \mathrm{~b}$ & 2,86 \\
Prata & $17,1 \mathrm{bc}$ & $77,5 \mathrm{a}$ & 2,82 \\
Transparente & $18,7 \mathrm{a}$ & $64,3 \mathrm{c}$ & 4,65 \\
Sombrite & $16,8 \mathrm{c}$ & $78,3 \mathrm{a}$ & 4,64 \\
Céu aberto & $17,2 \mathrm{bc}$ & $70,4 \mathrm{~b}$ & 7,04 \\
\hline
\end{tabular}

${ }^{1}$ Médias seguidas pela mesma letra não diferem entre si pelo teste de Tukey a $5 \%$ de probabilidade. 
Tabela 2 - Área foliar $\left(\mathrm{cm}^{2}\right)$ do conjunto de quatro plantas de rúcula cv. 'Folha Larga' no outono, em função da cobertura de túnel e do tipo de cobertura de solo. FCA/LNESP, Botucatu - SP, 2006.

\begin{tabular}{llllllc}
\hline & & & & & & \\
Cobertura do solo & Azul & Vermelho & Prata & PEBD* & Sombrite & Céu aberto \\
\hline MP & $899,7 \mathrm{AB}^{1}$ & $1029,1 \mathrm{abAB}$ & $1059,0 \mathrm{AB}$ & $1449,1 \mathrm{aA}$ & $672,1 \mathrm{~B}$ & $698,5 \mathrm{~B}$ \\
$\mathrm{MD}$ & 1123,6 & $1363,8 \mathrm{a}$ & 973,7 & $1339,2 \mathrm{ab}$ & 721,8 & 893,9 \\
$\mathrm{CA}$ & 945,2 & $971,3 \mathrm{ab}$ & 1181,9 & $1225,4 \mathrm{ab}$ & 614,9 & 907,6 \\
$\mathrm{SM}$ & 1133,5 & $630,7 \mathrm{~b}$ & 907,3 & $824,4 \mathrm{~b}$ & 699,6 & 866,8 \\
$\mathrm{CV}=28,8 \%$ & & & & & & \\
\hline
\end{tabular}

${ }^{1}$ Letras minúsculas comparam na coluna e letras maiúsculas comparam na linha, médias seguidas de mesma letra não diferem entre si pelo teste de Tukey a $5 \%$.

MP- mulching preto, MD- dupla face. CA- casca de arroz, SM- sem mulching.

* Filme plástico transparente de polietileno de baixa densidade de $100 \mu$

de filme transparente de PEBD ou telas vermelha, prata e azul e principalmente sobre mulching MP, proporcionaram na média melhores respostas agronômicas das plantas de rúcula considerando produção de matéria fresca, matéria seca, área foliar e peso específico foliar. O cultivo sob cobertura de túnel com sombrite e a céu aberto proporcionou resultados inferiores. Este último ambiente também teve a qualidade de folhas inferior, por apresentar peso específico foliar maior que o tratamento de cobertura com filme transparente de PEBD (Figura 1). Ainda, nos ambientes sob túneis com cobertura de PEBD e tela vermelha, as plantas cultivadas sobre os mulchings MP apresentaram as características produção de matéria fresca, matéria seca e área foliar superior ao mulching SM.

Quanto às respostas agronômicas das plantas de rúcula considerando produção de matéria fresca, matéria seca e área foliar, que conferem maior produtividade à rúcula, aquelas proporcionados sob túneis com coberturas de filme transparente de PEBD sobre mulching MP, foram mais adequadas que o ambiente com cobertura de túnel com sombrite e a céu aberto. Embora, a resposta das plantas cultivadas sobre mulching MD também tem sido superior em alguns tratamentos (Tabela 3). Esses resultados, provavelmente devem-se às condições climáticas proporcionadas pelas associações de cobertura de túneis e mulchings (Tabela 1). As temperaturas e umidades proporcionadas sob os túneis com cobertura PEBD e vermelha foram mais adequadas para as plantas cultivadas no inverno. Segundo TAIZ \& ZEIGER (2004), a associação de temperaturas mais elevadas e menor umidade relativa do ar proporcionam maior transpiração da planta e desde que estejam dentro da faixa de exigência da cultura, aceleram seu crescimento. Quanto ao efeito dos mulchings, é sabido que a utilização destes

Tabela 3 - Matéria fresca de plantas de rúcula (g por conjunto de quatro plantas), cv. 'Folha Larga ${ }^{\circledR}$, no outono, em função do tipo de cobertura de túnel e do tipo de cobertura de solo. FCA-UNESP, Botucatu (SP), 2006.

\begin{tabular}{llllllc}
\hline \multirow{2}{*}{ Cobertura do solo } & Azul & Vermelho & Prata & PEBD & Sombrite & Céu aberto \\
\hline $\mathrm{MP}$ & $51,3 \mathrm{~B}^{1}$ & $55,5 \mathrm{ab} \mathrm{AB}$ & $57,9 \mathrm{AB}$ & $88,7 \mathrm{a} \mathrm{A}$ & $37,5 \mathrm{~B}$ & $40,2 \mathrm{~B}$ \\
$\mathrm{MD}$ & $65,9 \mathrm{AB}$ & $77,7 \mathrm{a} \mathrm{A}$ & $53,1 \mathrm{AB}$ & $78,0 \mathrm{a} \mathrm{A}$ & $38,8 \mathrm{~B}$ & $57,0 \mathrm{AB}$ \\
$\mathrm{CA}$ & 50,8 & $52,7 \mathrm{ab}$ & 62,3 & $62,8 \mathrm{ab}$ & 30,8 & 51,5 \\
$\mathrm{SM}$ & 65,8 & $37,0 \mathrm{~b}$ & 46,8 & $43,9 \mathrm{~b}$ & 35,3 & 52,8 \\
$\mathrm{CV}-28,2 \%$ & & & & & & \\
\hline
\end{tabular}

\footnotetext{
${ }^{1}$ Letras minúsculas comparam na coluna e letras maiúsculas comparam na linha, médias seguidas de mesma letra não diferem entre si pelo teste de Tukey a $5 \%$ de probabilidade.

MP- mulching preto, MD- dupla face, $\mathrm{CA}$ - casca de arroz, SM- sem mulching.

* Filme plástico transparente de polietileno de baixa densidade de $100 \mu$.
}

Ciência Rural, v.43, n.5, mai, 2013. 


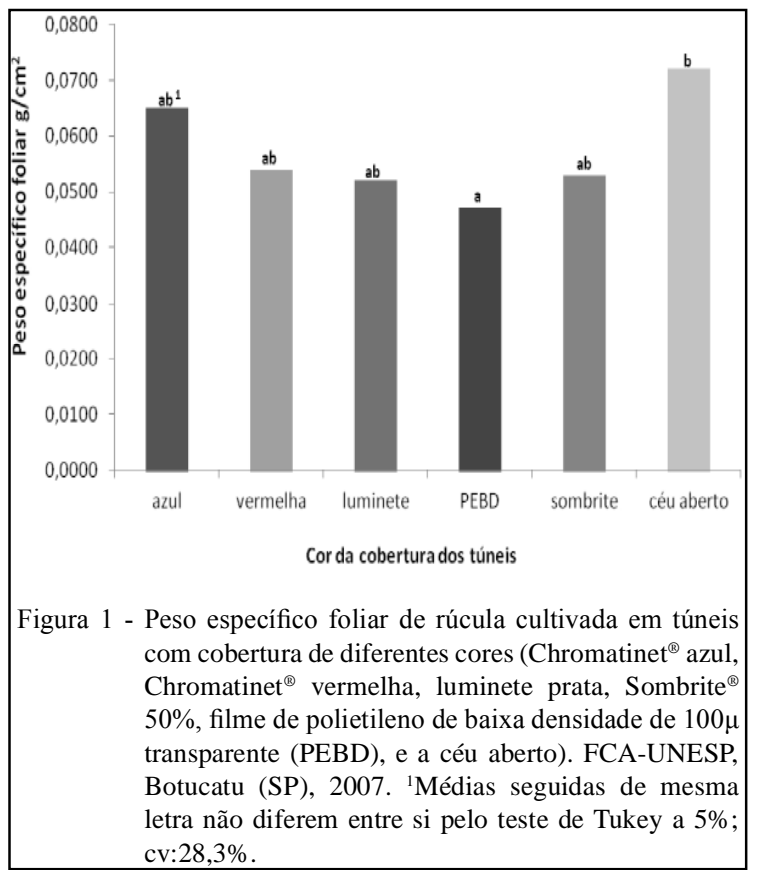

principalmente em cores e de polietileno aumenta a temperatura do solo e retém a umidade (TOSTA et al., 2010; GONÇALVES et al., 2005), que foi favorável às plantas em alguns tratamentos.

Embora amenor radiação fotossinteticamente ativa tenha aumentado a área foliar em comparação com o campo, com maior radiação, no túnel com sombrite ocorreu condições desfavoráveis para o plano desenvolvimento da rúcula. NOVO et al. (2008), constataram resultados semelhantes no estudo do efeito do sombreamento no desenvolvimento da rúcula.

Os resultados da característica peso específico foliar, obtido no presente trabalho, corroboram aos dados obtidos por PURQUEIRO (2005) e SCALON (2006) que obtiveram maior peso específico nas plantas estudadas, quando estas se encontravam a céu aberto. Segundo PURQUEIRO (2005), um dos critérios utilizado na avaliação da qualidade de hortaliças folhosas é o peso específico foliar, pois quanto menor for o peso específico foliar mais tenras as folhas estarão para o consumo, atendendo à preferência dos consumidores. Nesse aspecto, TAIZ \& ZEIGER (2004) relatam que o peso específico foliar relaciona a área da superfície foliar com a massa, estimando a espessura da folha que, sob maior intensidade luminosa, ocasiona o espessamento das células do parênquima paliçádico, aumentando o peso específico foliar e consequentemente aumentando a rigidez da folha.

\section{CONCLUSÃO}

$\mathrm{O}$ uso de telas pigmentadas na cobertura de túneis de cultivo, associado com mulchings, proporciona modificações no ambiente que favorecem as características de interesse agronômico de plantas de rúcula. Para se obter uma melhor produção de rúcula, recomenda-se utilizar túnel com cobertura de PEBD e o uso de mulchings.

\section{REFERÊNCIAS}

BLISKA, A. Plasticultura e Cultivo Protegido: Informação e Planejamento são Indispensáveis. Revista Plasticultura, Campinas SP, n. 2. p.8, 2011. Acesso em 22 set. 2012. Online. Disponível em: <http://www.asbraer.org.br/arquivos/bibl/56-caproducao.pdf>.

CEAGESP. Portal Ceagesp, Cotações, Ministério da Agricultura, Pecuária e Abastecimento, 2011. Acesso em 16 de nov. 2011. Online. Disponível em: <http://www.ceagesp.gov.br/cotacoes/ index_html>.

CUNHA, A.R.; GOTO, R. Túneis baixos com diferentes coberturas plásticas: alterações micrometeorológicas. In: XIV Congresso Brasileiro de Meteorologia, 2006, Florianópolis. Anais... Congresso Brasileiro de Meteorologia. São Paulo: Sociedade Brasileira de Meteorologia, 2006. V.1. p.14.

EMBRAPA, Sistema Brasileiro de Classificação de Solos. Brasília: Embrapa, 2006. 306p.

ESPINDOLA, C.R. et al. Levantamento pedológico da Fazenda Experimental São Manuel. In: Congresso Brasileiro de Ciências do Solo, 1973, Santa Maria, Anais... Santa Maria: SBCS, 1973. V.14. p.650-651.

FIGUEIREDO, G. Panorama da produção em ambiente protegido. Casa da agricultura, produção em ambiente protegido. 2011. Acesso em 23 mar. 2012. Online. Disponível em: <http://www. asbraer.org.br/arquivos/bibl/56-ca-producao.pdf $>$.

GONÇALVES, A.O. et al. Efeitos da cobertura do solo com filme de polietileno azul no consumo de água da cultura da alface cultivada em estufa. Engenharia Agrícola, Jaboticabal (SP) v. 25, n. 3, p. 622-631, dez. 2005. Disponível em <http://www.scielo.br/scielo. php? script=sci_arttext\&pid=S0100-69162005000300007\&lng $=$ en\&nrm=iso $>$. Acesso em: 23 Oct. 2012. doi. 10.1590/S010069162005000300007.

KÖPPEN, W.; GEIGER, R. Klimate der Erde. Gotha: Verlag Justus Perthes. 1927. 369p.

NOVO, A.A.C. et al. Influência do sombreamento sobre o crescimento e teores de nitrato em hortaliças folhosas em hidroponia. Revista Universo Acadêmico, Taquara (RS) 2008. Acessado em: 16 mar. 2010. Online. Disponível em: <http://www. univen.edu.br/universo_academico_13.asp>.

PURQUEIRO, L.F.V. Crescimento, produção e qualidade de rúcula (Eruca sativa Miller) em função do nitrogênio e da densidade de plantio. 2005. $119 \mathrm{f}$. Tese (Doutorado em Agronomia/Horticultura) - Curso de Pós-graduação em Produção 
Vegetal. Faculdade de Ciências Agronômicas, Universidade Estadual Paulista, Botucatu.

PURQUERIO, L.F.V.; TIVELLI, S.W. Manejo do ambiente em cultivo protegido. Manual técnico de orientação: projeto hortalimento. São Paulo: Codeagro, 2006. 83p.

RODRIGUES, I.N. et al. Desempenho de cultivares de alface na região de Manaus. Horticultura Brasileira, Brasília, v.26, n.4, dez. 2008. Disponível em: <http://www.scielo.br/scielo. php?script=sci_arttext\&pid=S0102-05362008000400020\&lng =en\&nrm=iso>. Acesso em: 23 out. 2012. doi. 10.1590/S010205362008000400020 .

ROCHA, M.A.V.; PURQUERIO, L.F.V. Produção de alface em função de diferentes coberturas de solo. Horticultura Brasileira. Brasília, v.27, n.2, p.475-479, ago. 2009. Disponível em: <http:// www.abhorticultura.com.br/eventosx/trabalhos/ev_3/A1876_ T2954_Comp.pdf>. Acesso em: 23 out. 2012.

SANTOS, L.L. et al. Luminosidade, temperatura do ar e do solo em ambientes de cultivo protegido. Revista de Ciências AgroAmbientais, Alta Floresta, v.8, n.1, p.83- 93, 2010.
SCALON, S.P.Q. et al. Desenvolvimento de mudas de aroeira (Schinus terebinthifolius) e sombreiro (Clitoria fairchildiana) sob condições de sombreamento. Ciência Agrotécnica, Lavras, v.30, n.1, p.166-169, 2006.

STRECK, L. et al. Sistema de produção de alface em ambiente parcialmente modificado por túneis baixos. Ciência Rural, Santa Maria, v.37, n.3, p.667-675, 2007.Disponível em: <http:// www.scielo.br/scielo.php?script $=$ sci_arttext \& pid $=$ S0103 $84782007000300011 \& \operatorname{lng}=\mathrm{en} \& \mathrm{nrm}=\mathrm{iso}>$. Acesso em: 23 out. 2012. doi.10.1590/S0103-84782007000300011.

TAIZ, L.; ZEIGER, E. Fisiologia vegetal. Porto Alegre: Artmed, 2004. 719p

TOSTA P.A.F et al. Utilização de coberturas de solo no cultivo de alface 'Babá de Verão' em Cassilândia (MS). Revista Brasileira de Ciências Agrárias; p.585-589, 2010. Disponível em: <http:// www.agraria.pro.br/sistema/index.p?journal=agraria\&page $=$ artic le\&op=viewArticle\&path\%5B\%5D=agraria_v5i1a209>. Acesso em: 30 de mai. 2012. doi:10.5039. /agraria.v5i1a209.

TRANI, P.E. et al. Tomateiro. In. RAIJ, B. et al. (E.d.) Recomendações de adubação e calagem para o Estado de São Paulo. Campinas, SP: IAC, 1997. (Boletim Técnico, 100) 279p. 